\title{
Formulation and evaluation of solid self micro emulsifying drug delivery system using aerosil 200 as solid carrier
}

\author{
*Durgacharan Arun Bhagwat, John Intru D’Souza \\ JJT University, Jhunjhunu, Rajasthan, India \\ Dept. of Pharmaceutics, Tatyasaheb Kore College of Pharmacy, Warananagar, Kolhapur, Maharashtra, India-416113
}

\begin{abstract}
Improvement of bio-availability of poorly water soluble drugs presents one of the furthermost challenge in drug formulations. One of the most admired and commercially viable formulation approach for this challenge is solid self micro emulsifying drug delivery system (S-SMEDDS). There are many techniques to convert liquid SMEDDS to solid, but an adsorption technique is simple and economic. Hence aim of present study was to develop S-SMEDDS of poorly water soluble drug Telmisartan (TEL) using Aerosil 200 as solid carrier. Liquid SMEDDS was prepared using Acrysol EL 135, Tween 80 and PEG 400 as oil, surfactant and co-surfactant and was converted to S-SMEDDS by adsorbing it on Aerosil 200. Prepared S-SMEDDS was evaluated for flow properties, drug content, reconstitution properties, DSC, SEM, in-vitro drug release and ex-vivo intestinal permeability study. Results showed that prepared S-SMEDDS have good flow property with $99.45 \pm 0.02 \%$ drug content. Dilution study by visual observation showed that there was spontaneous micro emulsification and no sign of phase separation. Droplet size was found to be 0.34 $\mu \mathrm{m}$ with polydispersity index of 0.25 . DSC thermogram showed that crystallization of TEL was inhibited. SEM photograph showed smooth surface of S-SMEDDS with less aggregation. Drug releases from S- SMEDDS were found to be significantly higher as compared with that of plain TEL. Ex-vivo intestinal permeability study revealed that diffusion of drug was significantly higher from S-SMEDDS than that of suspension of plain TEL. Study concluded that S-SMEDDS can effectively formulated by adsorption technique with enhanced dissolution rate and concomitantly bioavailability.
\end{abstract}

Key Words: Telmisartan, S-SMEDDS, adsorption technique, reconstitution properties, dissolution rate, ex-vivo intestinal permeability.

\section{INTRODUCTION}

Poor bioavailability is a trouble, frequently faced in the drug development process. Enhancement of bioavailability of poorly water soluble drugs becomes farthest challenge for pharmaceutical scientist. Most of new drug candidates reveal low solubility in water, which leads to poor oral bioavailability, high intra- and inter-subject variability and lack of dose proportionality. Various approaches should use to improve the dissolution rate of the drug. Among them, Self micro emulsifying drug delivery systems (SMEDDS) have shown great pledge for enhancing bioavailability of poorly soluble compounds. Con-

\footnotetext{
*Corresponding Author:

Durgacharan Arun Bhagwat, Research Scholar

JTT University, Jhunjhunu, Rajasthan

Dept. of Pharmaceutics, Tatyasaheb Kore College of Pharmacy

Warananagar, Kolhapur, Maharashtra, India 416113

E-mail: durgapharma@gmail.com

Contact No.: +919561350999
}

ventional SMEDDS are usually prepared in a liquid dosage form that can be administered in soft gelatin capsules, which have some disadvantages particularly in the manufacturing process and incompatibility problems with the shells of soft gelatin. Solid SMEDDS have recently been described and they surmount the disadvantages of liquid SMEDDS as well as exhibited more commercial potential and patient acceptability (Akhter et al., 2012; Bhagwat et al., 2012; Agarwal et al., 2009).

Many techniques are offered to convert conventional liquid SMEDDS to solid such as adsorptions to solid carriers, spray drying, spray cooling, melt extrusion, nanoparticles technology, supercritical fluid based methods, etc. But among these the adsorption technique is simple and just involves addition of liquid formulation onto carriers by mixing in a blender. The resulting powder may then 
be filled directly into capsules or, alternatively, mixed with suitable excipients before compression into tablets. A significant benefit of the adsorption technique is good content uniformity. The SMEDDS can be adsorbed at high levels up to $70 \% \mathrm{w} / \mathrm{w}$ on to suitable carrier (Katteboina et al., 2009).

TEL is Angiotensin II Receptor Antagonist, which is used in the prevention and treatment of Hypertension. TEL belongs to class II drug in BCS classification. One of the foremost problems with this drug is its low solubility in biological fluids, which results into poor bioavailability after oral administration. The solubility of TEL in aqueous medium is very low i.e. $0.078 \mathrm{mg} / \mathrm{ml}$ in water. Absolute bioavailability of the TEL is $42-58 \%$ and biological half-life is 24 hours that results into poor bioavailability after oral administration. Thus increasing aqueous solubility and dissolution of TEL is of therapeutic meaning (Kausalya et al., 2011; Bhagwat et al., 2012).

Hence present study aimed towards development of S-SMEDDS of TEL by adsorption technique using Aerosil 200 as solid carrier for enhanced bioavailability.

\section{MATERIALS AND METHODS}

Telmisartan was obtained as a gift sample from Glochem Industries Ltd. Vishakhapatnam, AP, India. Acrysol EL 135 was gifted by Corel Pharma Chem, Gujarat, India. PEG 400, Tween 80 and Aerosil 200 were obtained from S. D. Fine Chem., Mumbai. All other chemicals were of reagent grade.

\section{Preparation of Liquid SMEDDS}

Authors have already developed and evaluated liquid SMEDDS of TEL successfully by determining solubility of TEL in various oils, surfactants and cosurfactants and by constructing pseudo ternary phase diagram to identify micro emulsion region. From that satisfactory composition was selected to prepare liquid SMEDDS.

In brief TEL ( $20 \mathrm{mg} / 10 \mathrm{gm})$ was placed in glass vial. To this Acrysol EL $135(10 \% \mathrm{w} / \mathrm{w})$ added and warmed on water bath. To this oily mixture Tween $80(30 \% \mathrm{w} / \mathrm{w})$ and PEG $400(40 \% \mathrm{w} / \mathrm{w})$ was added. Then the components were mixed by gentle stirring and vortex mixing at $37^{\circ} \mathrm{C}$ until TEL was completely dissolved. Then the mixture was sealed in glass vial and stored at room temperature until used (Tang et al., 2008; Bhagwat et al., 2012).

\section{Preparation of S-SMEDDS}

S-SMEDDS was prepared by mixing liquid SMEDDS containing TEL with Aerosil 200 in 1:1 proportion. In brief liquid SMEDDS was added drop wise over Aerosil 200 contained in broad porcelain dish. After each addition, mixture was homogenized using glass rod to ensure uniform distribution of formulation. Resultant damp mass was passed through sieve no. 120 and dried at ambient temperature and stored until further use (Bandivadekar et al., 2011).

\section{Evaluation of S-SMEDDS}

\section{Flow properties of S-SMEDDS}

Angle of repose

The angle of repose of S-SMEDDS was determined by funnel method. Accurately weighed sample were taken in a funnel. Height of the funnel was adjusted in such a way that the tip of the funnel just touches the apex of the heap of S-SMEDDS powder. The powder were allowed to flow through funnel freely onto the surface. The diameter of the powder cone was measured and angle of repose calculated using the following equation (More et al., 2004):

$\tan \theta=\frac{h}{r}$

\section{Bulk density}

Both loose bulk density (LBD) and tapped bulk density (TBD) were determined. A quantity of $2 \mathrm{~g}$ of S-SMEDDS was introduced into a $10 \mathrm{ml}$ measuring cylinder. Initial volume was observed, the cylinder was allowed to fall under its own weight onto a hard surface from a height of $2.5 \mathrm{~cm}$ at 2 second intervals. The tapping was continued until no further change in volume was noted. LBD and TBD were calculated using the following formulae (More et al., 2004):

$\begin{aligned} L B D & =\frac{\text { Weight of powder }}{\text { Volume of packing }} \\ T B D & =\frac{\text { Weight of powder }}{\text { Tapped volume of packing }}\end{aligned}$

\section{Compressibility Index}

The compressibility of the granules was determined by Carr's Compressibility Index.

Carr's compressibility index $(\%)=\frac{(T B D-L B D)}{T B D} \times 100$ 


\section{Hausner ratio}

A similar index like compressibility index has been defined by Hausner. Hausner ratio can be calculated by formula:

Hausner ratio $=\frac{T B D}{L B D}$

\section{Drug content determination}

TEL content in S-SMEDDS was estimated using the UV method. S-SMEDDS was dissolved in sufficient quantity of methanol. The solution was sonicated for 10 mins for extraction of the drug in methanol and filtered. The absorbance of filtrate was read at $296 \mathrm{~nm}$ on UV- Visible Spectrophotometer (Patel et al., 2010).

\section{Reconstitution properties of S-SMEDDS}

Dilution study by visual observation

Dilution study was done to study the effect of dilution on S-SMEDDS, because dilution may better mimic the condition of stomach after oral administration. In this method, S-SMEDDS (100 mg) was introduced into $100 \mathrm{~mL}$ of double distilled water in a glass beaker that was maintained at $37^{\circ} \mathrm{C}$ and the contents mixed gently using a magnetic stirrer. The tendency to emulsify spontaneously and progress of emulsion droplets were observed with respect to time. The emulsification ability of S-SMEDDS was judged qualitatively "good" when clear microemulsion formed and "bad" when there was turbid or milky white emulsion formed after stopping of stirring (Nekkanti et al., 2010).

\section{Droplet size determination}

$10 \mathrm{mg}$ of S-SMEDDS formulation was diluted with $10 \mathrm{~mL}$ double distilled water in a beaker with constant stirring on a magnetic stirrer. The average Droplet size and polydispersity index of microemulsion from S-SMEDDS was assessed by lesser light scattering technique using Mastersizer 2000 Ver. 5.22 Serial Number: 34027-08 Malvern Instruments Ltd. Malvern, UK.

\section{Differential scanning calorimetry (DSC)}

Thermograms of pure drug, Aerosil 200 and SSMEDDS were obtained using Differential Scanning Calorimetry instrument equipped with an intracooler (TA Instruments, SDT-2960, USA). Indium standard was used to calibrate the DSC temperature and enthalpy scale. The powder samples was hermetically kept in the aluminium pan and heated at constant rate $10^{\circ} \mathrm{C} / \mathrm{min}$, over a temperature range
Table 1. Micromeritic properties and drug content of SSMEDDS.

\begin{tabular}{|c|c|}
\hline Properties of S-SMEDDS & Results \\
\hline Angle of Repose (degree) ${ }^{*}$ & $27.63 \pm 0.04$ \\
\hline $\operatorname{LBD}(\mathrm{g} / \mathrm{ml})^{*}$ & $0.54 \pm 0.12$ \\
\hline $\operatorname{TBD}(\mathrm{g} / \mathrm{ml})^{*}$ & $0.65 \pm 0.47$ \\
\hline Carr's Index $(\%)^{*}$ & $16.92 \pm 0.31$ \\
\hline Hausner Ratio* & $1.20 \pm 0.06$ \\
\hline Drug content $(\%)^{*}$ & $99.45 \pm 0.02$ \\
\hline
\end{tabular}

of $35^{\circ} \mathrm{C}$ to $350^{\circ} \mathrm{C}$. Inert atmosphere was maintained by purging nitrogen at the flow rate of $100 \mathrm{~mL} / \mathrm{min}$.

\section{Scanning electron microscopy (SEM) of S-SMEDDS}

Surface topography of the S-SMEDDS was investigated by SEM, operating at $20 \mathrm{kV}$. The sample was fixed on SEM stub and then coated with thin layer of platinum (JEOL, - 6360, JEOL Japan).

\section{In-vitro drug release study}

The in-vitro dissolution study of S-SMEDDS and plain drug were carried out using USP- type-II dissolution test apparatus (Veego, VDA-8DR ) in $\mathrm{pH}$ 1.2 and $\mathrm{pH} 7.5$ buffer solutions at $37 \pm 0.5^{\circ} \mathrm{C}$ with 50 rpm rotating speed. Samples of $5 \mathrm{~mL}$ were withdrawn at regular time interval of 5, 10, 15, 30, 60 and $120 \mathrm{~min}$ and filtered using $0.45 \mu \mathrm{m}$ filter. An equal volume of respective dissolution medium was added to maintain the volume constant. Drug content from sample was analyzed using UVspectrophotometer (Shimadzu-1800, Japan) at 296 $\mathrm{nm}$. All measurements were done in triplicate from three independent samples (Patel et al., 2010).

\section{Ex-vivo intestinal permeability study}

All experiments and protocols described in this study were approved by the Institutional Animal Ethics Committee (Ref. No. IAEC/TKCP/2012/09) and all experiments were conducted as per the norms of the Committee for the Purpose of Control and Supervision of Experiments on Animals (CPCSEA). Male Wister rat (250-300g) was sacrificed by $\mathrm{CO}_{2}$ inhalation method. Intestine was isolated and cleaned properly. Reconstituted solution of SSMEDDS and plain drug suspension was filled into the intestine which was tied at both the end. The tissue was placed in an organ bath with continuous aeration at $37^{\circ} \mathrm{C}$. The receptor compartment (organ tube) was filled with phosphate-buffered saline $\mathrm{pH}$ 


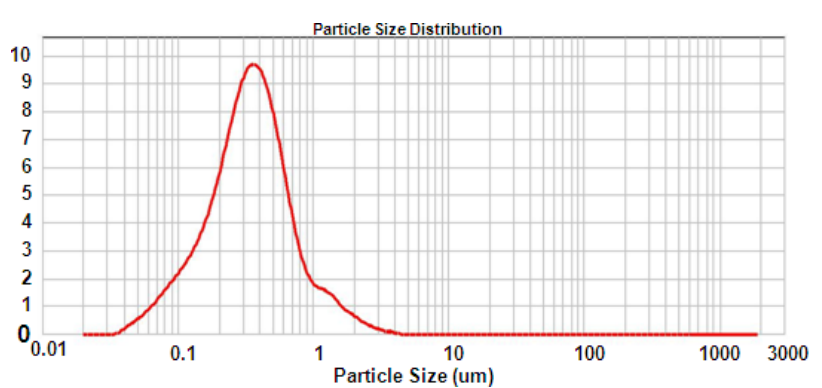

Figure 1. Mean droplet size of reconstituted S-SMEDDS.

7.4 with $1 \%$ sodium lauryl sulphate. At predetermined time intervals, samples were withdrawn from the receptor compartment. Fresh buffer was used to replenish the receptor compartment. The samples were analyzed spectrophotometrically at $296 \mathrm{~nm}$ for the content of TEL. The percent diffusion was calculated using PCP-Disso v2.08 software and plotted against time (Thakkar et al., 2011).

\section{RESULTS AND DISCUSSION}

\section{Evaluation of S-SMEDDS}

Flow properties of S-SMEDDS

Various micromeritic properties of S-SMEDDS of TEL are shown in Table 1. Results showed that SSMEDDS has good flow properties.

\section{Reconstitution properties of S-SMEDDS}

Dilution study by visual observation

A visual test was carried out to assess self emulsification of S-SMEDDS in $100 \mathrm{~mL}$ double distilled water at $37^{\circ} \mathrm{C}$ under gentle agitation. S-SMEDDS

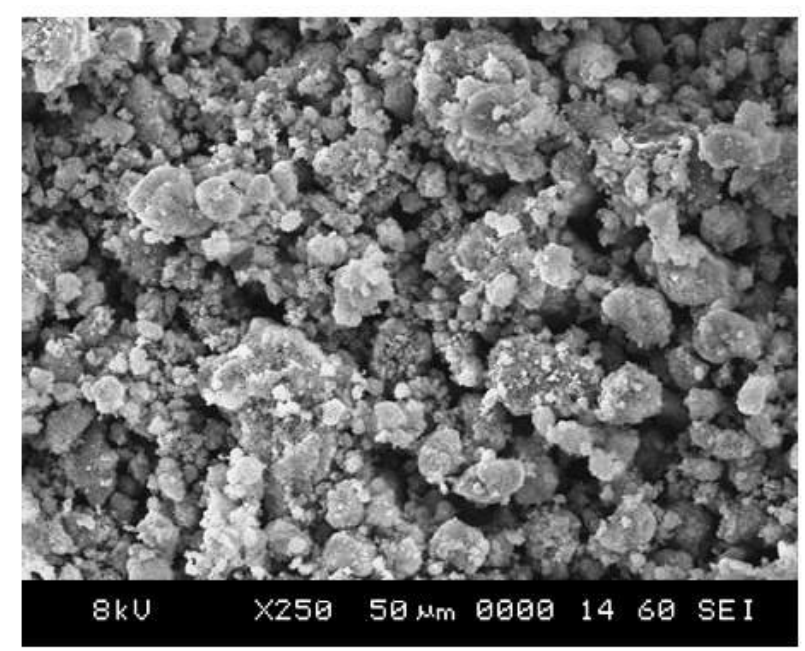

Figure 3. SEM of S-SMEDDS.

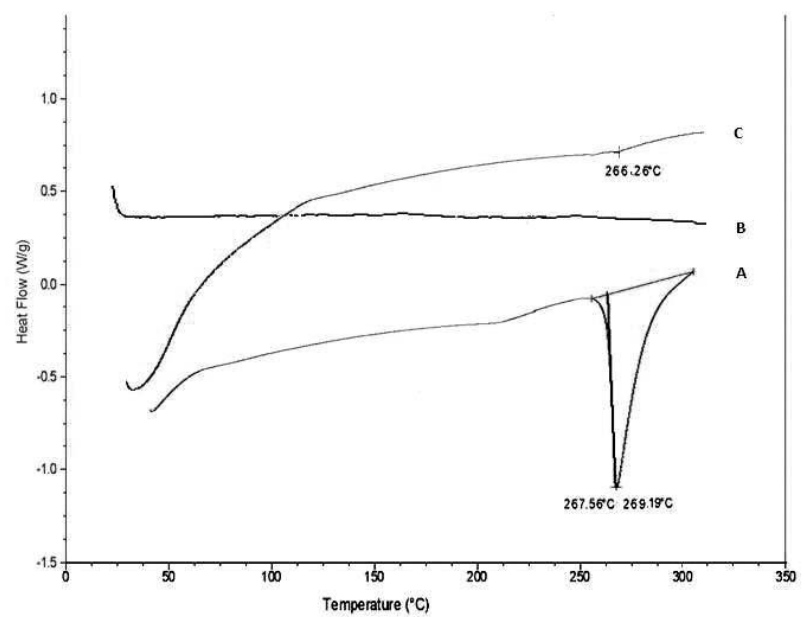

Figure 2. DSC curves of A) TEL B) Aerosil 200 C) S-SMEDDS.

showed spontaneous micro emulsification and there was no sign of phase separation or phase inversion of micro emulsion after storage of $2 \mathrm{~h}$.

Droplet size determination

Mean droplet size of reconstituted S-SMEDDS was found to be $0.34 \mu \mathrm{m}$ with polydispersity index 0.25 (Figure 1). S-SMEDDS showed polydispersity index less than 1, indicating uniform distribution of droplets throughout formulation.

Differential scanning calorimetry (DSC)

Figure 2 shows DSC curves of TEL, Aerosil 200 and S-SMEDDS. TEL shows sharp endothermic peak at near about $267.56^{\circ} \mathrm{C}$. The S-SMEDDS exhibit retained small endothermic peak for TEL and it may be due to solubilization of TEL in SMEDDS.

\section{SEM of S-SMEDDS}

Figure 3 showed that S-SMEDDS appeared as smooth surfaced S-SMEDDS particles, indicating that the liquid SMEDDS is adsorbed or coated inside the pores of Aerosil 200 with a lesser amount of aggregation.

\section{In-vitro drug release study}

Cumulative \% drug release of TEL in $\mathrm{pH} 1.2$ and 7.5 was found to be $96.55 \pm 2.56$ and $97.82 \pm 2.52$ respectively and that of plain TEL was found to be $29.35 \pm$ 1.36 and 31.47 \pm 2.06 respectively (Figure 4). This showed that drug releases from S- SMEDDS was found to be significantly higher as compared to plain TEL. From results it was also found that dissolution of TEL is $\mathrm{pH}$ independent. 


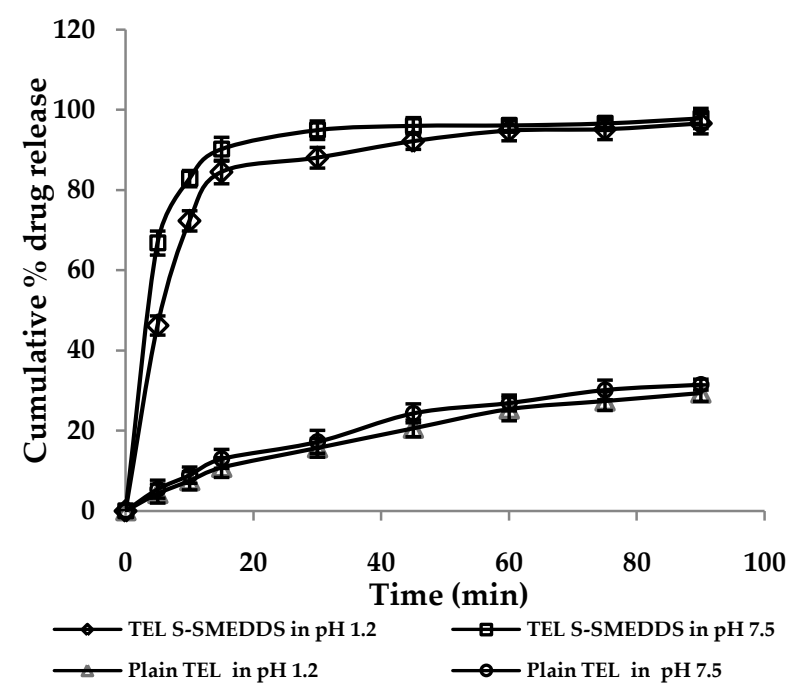

Figure 4. Cumulative \% drug release of S-SMEDDS and Plain TEL in pH 1.2 and 7.5.

\section{$E x$-vivo intestinal permeability study}

The results of the ex-vivo intestinal permeability study are shown in Figure 5. After $6 \mathrm{~h}$ of diffusion $70.38 \%$ of the drug was diffused from S-SMEDDS, while from plain drug suspension the diffusion was found to be $36.73 \%$. Thus, the amount of the drug diffused through the biological membrane has more when it is given in the form of S-SMEDDS. The enhancement in diffusion is due to formation of micro emulsion droplets (mean droplet size 0.34 $\mu \mathrm{m})$ in micrometer range and improved permeation of the TEL because of the presence of surfactant, which reduces the interfacial tension of formulation (Thakkar et al., 2011).

\section{CONCLUSION}

Study concluded that, S-SMEDDS of TEL prepared using Aerosil 200 by adsorption process showed good flow properties and drug content. After reconstitution it formed micro emulsion with micrometric range. Invitro drug release and Ex-vivo intestinal permeability was much higher than that of plain TEL. Hence adsorption process using Aerosil 200 as solid carrier may efficiently formulate S-SMEDDS which enhance dissolution rate and intestinal permeability and concomitantly bioavailability.

\section{ACKNOWLEDGEMENT}

We gratefully thank to Hon. Shri. G. D. Patil, Secretary, Shree Warana Vibhag Shikshan Mandal,

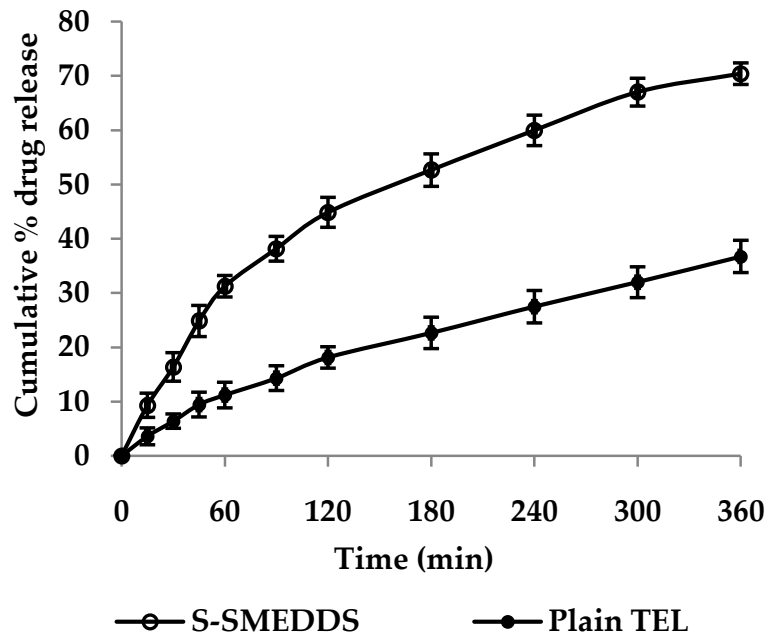

Figure 5. Ex-vivo intestinal permeability study of SSMEDDS and plain TEL.

Warananagar, Kolhapur, MS India, for constant inspiration and making available the necessary facilities and Corel Pharma Chem, Gujarat, India for providing gift sample of Acrysol EL 135.

\section{REFERENCES}

Agarwal V., Siddiqui A., Ali H., Nazzal S. (2009), Dissolution and powder flow characterization of solid self-emulsified drug delivery system (SEDDS), Int. J. Pharm. 366:44-52. [DOI] PMid:18832019

Akhter S., Hossain Md. I. (2012), Dissolution enhancement of Capmul PG8 and Cremophor EL based Ibuprofen Self Emulsifying Drug Delivery System (SEDDS) using Response surface methodology, International Current Pharmaceutical Journal, 1(6): 138-150. [DOI]

Bandivadekar M. M., Pancholi S. S., Shelke N. (2011), Preparation and characterization of solid SMEDDS by adsorbent techniques to improve dissolution profile of poorly aqueous soluble drug Ramipril, International research Journal of Pharmacy, 2(6): 85-90.

Bhagwat D. A., D'Souza J. I. (2012), Development of Solid-Self Micro Emulsifying Formulation to Improve Oral Bioavailability, International Journal of Therapeutic Applications, 1: $38-41$.

Bo Tang, Gang Cheng, Jian-Chun Gu and Cai-Hong Xu. (2008), Development of solid self-emulsifying drug delivery systems: preparation techniques and dosage forms, Drug Discovery Today, 13:13/14, 606-612. [DOI] PMid:18598917

J. Kausalya, K. Suresh, S. Padmapriya, A. Rupenagunta, B. Senthilnathan (2011): Solubility and Dissolution Enhance- 
ment Profile of Telmisartan using various techniques, Int.J. Pharm Tech Res., 3(3): 1737-1749.

Katteboina S., P. VSR Chandrasekhar, S. Balaji (2009), Approaches for the development of solid self-emulsifying drug delivery systems and dosage forms, Asian Journal of Pharmaceutical Sciences, 4 (4): 240-253.

More H. N., Hazare A. A. (2004): Practical Pharmaceutics (Physical pharmacy), Manas Prakashan, Kolhapur, $1^{\text {st }}$ Ed., 86-105.

Nekkanti V., Karatgi P., Prabhu R., Pillai R. (2010), Solid selfmicroemulsifying formulation for candesartan cilexetil, AAPS Pharmsci., 11: 9-17. [DOI] PMid:20013081 PMCid:2850472
Patel P. A., Patravale V. B. (2010): International Journal of

Pharma Sciences and Research (IJPSR), 1(8): 282-292.

Thakkar H., Nangesh J., Parmar M., Patel D. (2011), Formulation and characterization of lipid based drug delivery system of raloxifene microemulsion and self microemulsifying drug delivery system, Journal of Pharmacy and Bioallied Sciences, 3(3): 442-448. [DOI] PMid:21966167 PMCid:3178953 